\title{
Learning in the Virtual World: the Pedagogical Potentials of Massively Multiplayer Online Role Playing Games
}

\author{
Tao Wang YU \\ Centre for Assessment Research and Development \\ The Hong Kong Institute of Education \\ Room 09, 2/F, B1, 10 Lo Ping, Tai Po, N.T., Hong Kong \\ Tel: 852-2948-8061Ｅ-mail: twyu@ied.edu.hk
}

\begin{abstract}
A much more attractive way to use the internet was discovered. Users are represented by avatars in the fantasy persistent 3D world, and the avatars apparently come to occupy a special place in the hearts of their creators (Castronova, 2001). At present, millions of people worldwide have accounts to some kind of virtual environments. Virtual world may soon become the primary venue for all online activities (Castronova, 2001) including learning. Imagine that one can gain knowledge and skills by social interactions in virtual worlds. A massively multi-student online learning environment (MMOLE) is a pedagogically designed space where students would spend much time learning online by doing and interacting with others. Furthermore, massively multiplayer online games (MMOGs) or massively multiplayer online role playing games (MMORPGs) allow individuals, through their avatars, to learn in the service of games goals and through problem solving and collaboration. This article aims at exploring the pedagogical potentials of virtual worlds. The strengths and weaknesses will be outlined and some of the issues will be discussed through case studies. Hopefully, lessons can be learned and the future virtual worlds can become a more powerful and effective environment to engage students in learning.
\end{abstract}

Keywords: Virtual world, Online learning, Online games

\section{Why learn in virtual worlds?}

Students are facing the new challenges of the $21^{\text {st }}$ century induced by globalization, information explosion and international competition (Cheng, Chow \& Mok, 2004). Higher order skills or so-called $21^{\text {st }}$ century skills are fundamental to the success of knowledge workers (Galarneau \& Zibit, 2007). Learning goals including cultivating critical thinking, developing generic skills, life-long learning, seeing things in multi-perspectives, collaborating with others as well as enhancing social awareness become more important. At present, the mode of classroom teaching and learning, and the deployment of learning time are largely content-oriented and teacher-centred (Slator et al, 2002; Galarneau \& Zibit, 2007). Teaching-to-the-test and rote-learning are not uncommon. Emphasis is often on factual knowledge which is easier and more objective to assess (Lee, 1991). Much time is allocated on preparing examinations and memorizing facts out of context rather than developing high order thinking skills and life-long learning attitude. As pointed out by Madaus that (as cited in Weeden, Winter \& Broadfoot, 2002), when test results are the sole or even a partial arbiter of future educational or life choices, society tends to treat test results as the major goal of schooling rather than a useful but fallible indicator of achievement. But in fact, students should be learning concepts, process, or ideas that lie behind it rather than just test items (English, 2000). Shepard (1997) points out that the teaching-to-the-test literature has repeatedly shown practice with familiar formats reduces the likelihood that students will be able to use their knowledge when they encounter problems posed in even slightly different ways. In contrast, students should learn how to extend their knowledge and apply it in new situations. They should be able to use insights from previous lessons to generate new knowledge rather than just within the narrow perimeters of a given lesson or set of content. Students can only build up knowledge through active participation (Reid, 1994). The conventional teacher-centred approach of teaching puts students in a passive position. Learning is effective only when learners can relate what they already know to what they are going to acquire. As a result, teachers should make reference to the cognitive abilities and knowledge base of their students in deciding the teaching contents. To make learning meaningful, students must be able to relate their knowledge to life experiences and interact with others. Students cannot internalize their knowledge and apply it in other situations if such knowledge is acquired merely by rote-learning (Law, 2005). Moreover, Glasersfeld (1989) suggests that learning as a constructive activity. Knowledge cannot be reduced to a stock of retrievable 'facts' but concerns the ability to compute new results. In Piaget's term, it is operative rather than figurative. 
Virtual world provides a suitable platform for putting the above ideas to practice. The focus of learning should be on learning how to learn, think and create. The learning can be a discovering and reflecting process. The traditional site-bounded teacher-centred paradigm should be changed into more student-centred oriented. Pedagogical practices should enable students to develop critical voices and engage in critical analysis and to make choices regarding what is most desirable and morally appropriate for living in a just and democratic society (Jenlink \& Jenlink, 2005). In such a paradigm shift, the nature of instruction inevitably has to change (Cheng, Chow \& Mok, 2004).

Gee (2007) pointed out that to deliver good learning would indeed be via game-like technologies. Rieber (1996), as cited in Sugumaran (2008), states that, "Research from education, psychology, and anthropology suggests that play is a powerful mediator for learning throughout a person's life" MMORPGs have the capacity to support collaborative learning approaches (De Freitas \& Griffiths, 2007) and MMOLE is designed to engage learners and to keep motivation levels high. The virtual environments can also help them learn deep content and higher order skills (Dede et al, 2005). It is evident that high engagement and interactions (Prensky, 2006), and individualized learning are critical for enhancing motivation, communication, a diverse range of skills and intellectual development in the educational process (Moore, 1989; Riding, 1999; Hobbs, 2002; Anderson, 2002, as cited in Wang, 2004). Students with diverse abilities and learning styles can also benefit from the experience. They can learn at their own pace and use their own strategies; and they are more intrinsically than extrinsically motivated (Wang, 2004). Students can enjoy a real sense of agency, ownership, and control (Gee, 2007). Learning becomes more active and fun as students' avatars walk around in the virtual environment to ask questions, solve problems and socialize. Visualizing instead of imagining also helps to engage student and develop deeper understanding. Furthermore, there is no geological limitation and also students are allowed to analyze the lesson later with a different perspective. Also, in virtual worlds, players are encouraged to take risks, explore, and try new things as the consequences of failure is lower (Gee, 2007). Conrad and Donaldson (2004) added that it is helpful to remember that some of the best lessons are learned from failure and subsequent reflection. When there is acceptance of learning from mistakes, students will take meaningful and creative chances.

\section{Case studies}

The study by Galarneau and Zibit (2007): Online Games for $21^{\text {st }}$ Century Skills, pointed out that players of MMOGs develop $21^{\text {st }}$ century skills in a spontaneous and holistic way as a by-product of play, even though learning these skills is not a direct goal of these games. For instance, an MMORPG called Everquest is designed in a way that makes grouping essential for achieving success. Hence, players must practice teamwork and collaboration, often with diverse groups of people to solve problems, in order to achieve. To be able to create, share, and master knowledge in MMOG environments is also important. Players must learn the social skills in order to get answers they need when they need them. Some become experts and are more than happy to be consulted. They establish themselves as authoritative (Beavis, 2004). Not only did they contribute to the virtual environment, but also gained invaluable social capital and genuine friendships, which could help them make progress on an emotional level. Moreover, through playing and sharing information, they have the chance to learn how to distinguish what is valid and what is erroneous - an important and difficult $21^{\text {st }}$ century skill to master. MMOGs also provide a platform to develop skills such as self-organize into groups, self-marketing, negotiation, and conflicts mediation. In MMOGs, often leaders come from unexpected corners (Beck \& Wade, 2006; Galarneau \& Zibit, 2007). In virtual world, players are more equal and are judged by their characters' actions. People are affiliated by their commitment to a common endeavour, not primarily by their race, class, ethnicity, or gender (Gee, 2007). It is a space in which people can establish their presence, identity and meaning in ways that might not be accessible or permissible in their everyday lives. A youngster, who seldom has the chance in real world, could lead a group of adults to a battle or complete a mission. Exploring other facets of individuals which may have gone unexplored, such as leadership, may lead to significant changes in their careers or perspectives. To sum up, Galarneau and Zibit have argued that players will pick up some knowledge that actually has some use in the real world, and learning is done in the service of game goals and through problem solving. The commercial available MMOGs are easy to get and relatively cheap compare to MMOLEs. However, one drawback of using available MMOGs in learning is that the games are not designed for specific learning goals. Therefore, if we do not have the budget to build a MMOLE and deploy a course, educators would need to figure out how to adapt an existing MMOG for pedagogical purposes.

In Foreman and Borkman's (2007) study: Learning Sociology in a Massively Multistudent Online Learning Environment, The Sims Online was used to conduct student learning exercises for Sociology 101 and Sociology 310 courses. The successful MMORPG is reformulated as an MMOLE so that appropriate learning goals can be achieved predictably and consistency. Students would develop their understanding of sociological principles through structured interactions within a set of simulated social scenarios. The results suggested that students had several levels of analytical or interpretive ability, and can matched distinct sociological terms with their instantiation in the game. However, major topics in sociology like ethnic diversity or discrimination were rarely dealt with, or simply cannot be dealt with. In fact, The Sims Online is a simplified world lacking the diversity and complexity of real life. The inhabitants are all good looking, young, well toned and have no physical distraction. Job variety is limited. This social 
system does not have the status and job prestige hierarchies one finds in real world. Therefore, course designers should understand the limitations of the chosen MMOLE and be careful in selecting specific learning goals of the MMOLE.

Foreman and Borkman (2007) also suggested that MMOLE should be organized into a "level progress" so that learners would have to complete a level, requiring a demonstration of learning, before moving on to the next. To reach the highest level would demonstrate a thorough understanding of the subject. The good news for both teachers and students is that no external assessment will be needed. However, we must aware that in current assessment practices, teachers and test items play important roles in measuring student ability. The method has been relatively effective and used for a long time. The validity and reliability of the traditional assessment can be checked, whereas the instrument to measure student achievement in virtual world has yet to be validated. Although some studies have tried to establish how MMOLEs can implement assessment such as using log file data and "Letters to the Mayor" in River City (Ketelhut et al, 2006), the development of assessment tools embedded in the system is still in early stages. Slator et al (2002) mentioned that the Worldwide Web Instructional Committee is developing a strategy and interface to a subjective evaluation of student progress that relies on player recall rather than objective recognition. In fact even in the real world, it is not always easy to translate learning outcomes, such as creative problem solving strategies or heightened abilities to collaborate, into quantitative measures that could be entered into grade books (Sandholtz et al, 1997). The important tasks - assessment and diagnosis of student skills in virtual world, have to be accomplished soon. Hence, more research on assessing learning outcomes in MMOLEs will be needed. But until then, we must be careful in interpreting the results and bear in mind that this kind of assessment method is not yet thoroughly investigated.

In the study: Fostering Motivation, Learning, and Transfer in Multi-User Virtual Environments (Dede et al, 2005), an MMOLE called River City is designed to teach scientific inquiry skills to middle school students. The main learning goal is to discover why the residents of River City are getting ill. Collaborative teams of students explore, analyze, and report on water-related health problems through scaffolding their inquiry and managing complexity - mimic to real world scientific inquiry process (Bitter \& Legacy, 2008). This is similar to playing Metal Gear Solid and The Elder Scrolls II: Morrowind. The games make players think like scientists and game play is built on a cycle of "hypothesize, probe the world, get a reaction, reflect on the results, reprobe to get better results," a cycle typical of experimental science (Gee, 2007). The MMOLE also provides a pedagogical vehicle for situated learning - learning that takes place in the same context in which it is applied (Lave \& Wenger, 1991; Gee, 2007), which is something not easy to create in normal classrooms. Other important design elements in the River City MMOLE include optimal level of challenge and autonomy, which help to engage and motivate students. The research use both qualitative and quantitative methods to investigate what features of the design do students find motivating and how do these features support learning. The results showed that students' thoughtfulness of inquiry and self-efficacy in science increased. Furthermore, students enjoyed exploring the unknown. Designing the scenario around a mystery can capture student curiosity, an important feature of designing for motivation (Leeper \& Malone, 1987, as cited in Dede et al, 2005). Other features students liked include collaboration with teammates, autonomy, communication with residents of River City, the right challenge, visualization of information, actively walking around and working like a scientist and using tools. One interesting finding is that when implementing the MMOLE in class, absentee rates go down. More importantly, students who tend to be bored by science become engaged and feel better about their abilities in learning science. But one point teachers should aware is that they may need to point out the difference between the learning environment and the real world processes or procedures they present to their students. Reality is more than the learning environment (Maddux et al, 1997). It is more complex and also more dangerous if you want to perform experiments.

Delwiche (2003) wrote in his paper, MMORPG's in the College Classroom, that role-playing games forced gamers to shift perspective and imagine the world through different eyes. Luff (2000), as cited in Delwiche (2003), referred role-playing as "the ultimate empathy exercise." As pointed out by Gee (2007), people really know what words mean only when they can hook them to the sorts of experiences they refer to, that is, to the sorts of actions, images, or dialogues to which the words relate. MMORPG in learning can be used for professional training as well, for example, training social workers, doctors, nurses and soldiers etc. In Delwiche's study, college students tried to learn the fundamental principles of social science research by role-playing the part of ethnographers in the online game Everquest. The class was claimed a success and the goals were accomplished. However, one may be suspicious about the trueness of the responses from computer-mediated data collection where gestures and facial expressions, which appear naturally and may contain useful information, cannot be seen by the virtual ethnographers. Even though some avatars may have some kind facial expressions, but they are made consciously and intentionally. After all, either telling the truth or telling a lie in virtual world has little consequence. In fact it is quite common for cyberspace users not to disclose personal information to others and use fade identities. Some may feel safer in answering intimate questions in virtual world, but for those who have reservations, instead of not answering the questions, may give you false answers with less hesitation because they are not physical seen by the ethnographers.

In Steinluehler's study (2004), Lineage was the chosen as the MMOG environment for investigation. It suggested that the mechanisms for learning entailed in MMOGs are contingent on the games not only as a designed object but also as a 
social practice. The design of learning environments is not just a matter of getting the curricular material right but is crucially also a matter of getting the situated, emergent community structures and practice right. You not only "have to play to learn," (Turkle, 1995, as cited in Steinluehler, 2004), but you also need to play with others to develop genuine expertise. Participation in virtual community can assist in building the skill of interdependence in students, which might help them in turn to build creative skills (Blumenthal, Inouye, \& Mitchell, 2003, as cited in Kock, 2008). In the MMOG World of WarCraft, players play on teams where each player has a different set of skills. Each player must master a specialty and at the same time understand enough of each other's specializations to coordinate with them (Gee, 2007). Gee, as cited in Galarneau and Zibit (2007), also pointed out that a major shift is to understand that people are part of network resources, distributed across the vastness of physical and virtual space. Moreover, Bandura's research (1991) showed that people learn not only from direct experience but also from observing others. Gee (2007) points out that game play actually has its social nature. Therefore, it is not surprising that MMOGs have been found to foster bridging ties rather than decreasing social and civil interactions (Jakobsson \& Taylor, 2003; Yee, 2006; Beck \& Wade, 2006).

The paper by De Freitas and Griffiths (2007) argues that MMORPGs have the capacity to support intrinsic motivation and so help to engage learners and collaborative processes. Some cases of using MMORPGs, including Mekong e-Sim, StrikeCOM and Full Spectrum Command, in learning and training were discussed. A wide range of learning areas were covered - geography and engineering education, military training, and developing cognitive skill such as leadership, decision making and ability to keep calm under pressure etc. Although results are encouraging, De Freitas and Griffiths believe that more intense study still needs to be conducted to investigate the benefits of learning in virtual worlds and the pedagogical implications. In particular, as indicates by the cases, the potential for supporting effective collaborative and simulation-based learning approaches does merit further research. Gredler (1996), as cited in Sugumaran (2008), also agrees that the major problems instructional designers encounter are that there are no available comprehensive design paradigms and the lack of well-designed research studies. In fact, only a few guidelines or models in the literature exist to guide instructional designers through the pain-staking process of creating a game-like learning environment for students (Sugumaran, 2008).

The study by Childress and Braswell (2006) gives examples using partner activities and group activities to deliver an online graduate-level Foundation of Instructional Technology course through Campus: Second Life - a special version of Second Life for educators to use in classes. It illustrates that the highly social attributes of MMORPGs make them rich environment for cooperative learning-based activities. Real-world learning experiences previously available only through face-to-face interaction can now be replicated with the aid of online role-playing scenarios. Students from different locations can share their ideas and findings with the entire class in their virtual classroom after planning, researching and work allocation. The cooperative learning technique would help students to develop higher order skills. It is found that teacher and students spend more unofficial time together outside of the typical class session (Neeson, 2006, as cited in Wikipedia). Unfortunately, for most beginners, to learn how to navigate in MMORPG environments takes time. Some students would have difficulty mastering game mechanics, especially when the game interface is complicated. Some even showed frustration with the steep learning curve (Delwiche, 2003). But as MMORPGs become easier to use, more sophisticated, offering increased interactive and realism, they may one day become the preferred platform for cooperative learning activities (Childress \& Braswell, 2006). Furthermore, advance in artificial intelligence will help to create virtual world pedagogical agents that can customize materials for each individual learner.

\section{Some issues to be addressed}

Some people criticize that many games in virtual worlds contain violence and may promote violent behaviour in real world. However, Castronova (2007) argued that people who do all the fighting in virtual worlds, their desire to get into real world fights will be minimal. The bloodlust is satisfied. A study by (Barnett 2008) found that the players were more calm or tired after playing violent games. However, results did vary among the various demographic groups. Although, some literature reviews suggest that not enough evidence has yet been gathered to link video games in general and social online games in particular with violence (Kirsh, 2006, as cited in Murphy, 2007), other reviews indicate such a link (Anderson \& Bushman, 2001; Anderson, Gentile, \& Buckley, 2007, as cited in Murphy, 2007). Research by Williams and Skoricon (2005) on violent video games does suggest that play leads to aggressive behavior. Beck and Wade (2006) remind us that results are inconclusive. It is still a matter of great debate among academics. Hence, whether violent behaviour and violent gaming is correlated still needs to be investigated further. Sadly, we have already seen incidents of seemingly obsessed online gamers replicate their avatars actions have killed and injured people in real world. In 2003, two young people were shot by two teenagers, who in statements to investigators claimed their actions were inspired by Grand Theft Auto III. Also, reports of racist groups using computer games such as Ethnic Cleansing to promote violence against ethnics groups (Gee, 2007) do raise concerns.

Addiction can be a serious problem. It may deteriorate family relationships, cause people to neglect more important priorities and lead to psychological disorders (Chan, 2006). MMOG is becoming a popular form of entertainment as well as a major mechanism of socialization (Steinkuehler, 2004), despite its purported addictive quality for those who 
plug in (Jewels, 2002, as cited in Steinkuehler, 2004). Would the attractive virtual world suck even more people in and get them addicted when it is introduced in class? In the study by Delwiche (2003), college students were actively immersed in Everquest for a whole quarter. Although, a few of them became heavily involved, at the end the whole class was strong enough to cancel their accounts. However, based on the low sample size of 36, one must not extrapolate to the boarder population, especially to those primary and secondary students with more leisure time and less self discipline. In fact, two former Everquest addicts contacted Delwiche and discussed the danger of building class around Everquest. The nature of the game is especially alluring to people whose lives are lacking meaning and substance. Therefore, students of all ages must be warned the potential risks of addiction and support should be available to them when virtual world is adapted in class.

Another problem in introducing MMOLEs and MMOGs in class is that our classrooms and teaching were not designed for this (Prensky, 2006). It would require teachers' smart thinking and planning to make it work. To do it successfully, it is important to know the games and the technology well. Unfortunately, for most teachers, adopting MMOGs and MMOLEs in class are relatively new to them. They have not been trained for it and many of them have not even played such games before. To fully exploit the power of technology, teachers need adequate training and support (Sandholtz et al, 1997). Even though more time and resources for technology training are given, the current methods of professional development focus on learning computers rather than on learning how to integrate computers into the curriculum (Sandholtz et al, 1997). New forms of teacher development need to be created that show teachers how to use virtual worlds to its fullest potential, and at the same time influenced teachers' attitudes toward teaching, their self-efficacy, and their beliefs about their students. Therefore, if we really want to employ virtual world in education, the nature of teacher education inevitably has to make some changes.

One of the major obstacles to overcome, beside technical problem, is that the general view that computer-based games are only for fun and not educational (Bitter \& Legacy, 2008; Prensky 2006). But many literatures have already provided evidence that video and computer game playing, done appropriate, is actually very beneficial to today's "Digital Native" kids, who use them to prepare for life in the $21^{\text {st }}$ century (Prensky, 2006; Galarneau \& Zibit, 2007). Also, through good game design we can leverage deeper and deeper learning as a form of pleasure in people's everyday lives, without any hint of school or schooling (Gee, 2007). Therefore, it is important to gain the support and acceptance from school administrators to experiment this new way of teaching and also let all educators and parents understand the educational potential of the increasingly popular technology.

Students spend much time in virtual environments. However, as reminded by Castronva (2007), they have to be lured back to the real world to learn too. To get them back, learning have to apply some of the techniques of applied hedonics. The implication is that education will have to become more fun. In fact, teachers can use the principles behind good, complex games to make teaching more game-like, and therefore more interesting and engaging to students (Prensky, 2006).

Although virtual worlds are good ways of communicating and interacting between students and teachers, this is not a substitute for actual face-to-face meetings. When using virtual worlds, there are the downsides in that you lose the body language and other more personal aspects. As shown in a study in (Chris Evans, Jing Ping Fan, Lifelong learning through the Virtual University, as cited in Wikipedia) that a majority of students have rejected the idea of a completely virtual mode of study. From a sound pedagogical perspective, learners still need teacher guidance and assistance in a variety of areas for their development (Wang, 2004).

\section{Conclusion}

People are enormously capable when given space and motivation (Galarneau \& Zibit, 2007). As we can see, the studies showed the effectiveness and potential of virtual world in education, and the results are encouraging. Other research has also told us that computer games can be considered powerful tools for increasing learning (Dempsey, Lucassen, et al., 1998, as cited in Sugumaran, 2008). So, is learning in virtual world the way to go? Delwiche (2003) also reminded us that, in most situations, traditional methods of instruction will work just fine. Hence, to make learning more effective, it is wise to use more complete and wider variety in learning techniques. That is to integrate both traditional paper based and technology based methods. They can be complementing each other and hence a hybrid curriculum might be more desirable. Boud (1999) also pointed out that in designing courses, it is critical to constructively align learner's needs, teaching and assessment methods, taking into account socio-cultural factors: learner's attributes and economics to ensure efficiency and cost effectiveness. Technology can help, but it is not a substitute for, careful curriculum planning, inspired examples and good teaching paradigms (Stewart, Kemp \& Batrum, 2001). It is clear that further research is required to explore the psychosocial benefits of learning in the complex but little understood virtual worlds. An evidence base should be built for researchers from different disciplines (De Freitas \& Griffiths, 2007) and the implications for learning design should also be more closely studied. It is critical to understanding how effective learning can be achieved through proper integration between pedagogy, organization and technology.

The idea of using virtual worlds in education and training is relative new to most educators. Nevertheless, educators are 
the main players in the struggle for positive educational change and must know how to decide on changes and how to implement them effectively. Pedagogical innovations and technical improvements in virtual worlds will lead to new ways of learning and new models of teaching. It is up to the creativity of educators and to extend the limits of using virtual worlds in learning. After all, what is worth fighting is ultimately the needs of learning among and caring for students.

Virtual worlds may soon become one of the most important forums for human interaction, on a level with telephones. In that role, they may induce widespread changes in the organization of Earth society (Castronova, 2001). Impact to learning and teaching practices is inevitable. Perhaps, what we really need most is a vision of what education will be like in the future. As the proverb says, as cited in Galarneau and Zibit (2007), "Vision without action is a dream; action without vision, a nightmare."

\section{References}

Bandura, A. (1991). Social cognitive theory of self-regulation. Organizational Behavior and Human Decision Processes. 50(2), 248-287.

Beavis, C. (2004). Good game: text and community in multiplayer computer games. In I. Snyder, \& C. Beavis (Eds.), Doing literacy online. Teaching, learning, and playing in an electronic world. Cresskill, New Jersey: Hampton Press, Inc.

Beck, J. C., \& Wade, M. (2006). The kids are alright. How the gamer generation is changing the workplace. Harvard Business School Press.

Bitter, G. G., \& Legacy, J. M. (2008). Using technology in the classroom (7th ed.). Boston, Mass.: Pearson/Allyn and Bacon Publishers.

Castronova, E. (2001). Virtual Worlds: A First-Hand Account of Market and Society on the Cyberian Frontier. Indiana University Bloomington - Department of Telecommunications; CESifo (Center for Economic Studies and Ifo Institute for Economic Research). Working Paper Series No. 618. [Online] Available: http://papers.ssrn.com/sol3/papers.cfm?abstract_id=294828 (August 3, 2008).

Castronova, E. (2007). Exodus to the virtual world: how online fun is changing reality. Palgrave Macmillan.

Chan, J. (2006). Unhealthy Gaming Habits and Addiction. [Online] Available: http://www.ocf.berkeley.edu/ jenchan/index.html (December 9, 2008).

Cheng, Y. C., Chow, K. W., \& Mok, M. M. C. (Eds.).(2004). Reform of teacher education in Asia-Pacific in the New Millennium. Trends and challenges. Kluwer Academic Publishers.

Childress, M. D., \& Braswell, R. (2006). Using Massively Multiplayer Online Role-Playing Games for Online Learning. Distance Education, 27(2), 187-196.

Conrad, R., \& Donaldson, J. (2004). Engaging the online learner. Jossey-Bass.

De Freitas, S., \& Griffiths, M. (2007). Online gaming as an educational tool in learning and training. British Journal of Educational Technology, 38(3), 535-537.

Dede, C., Clark, J., Ketelhut, D., Nelson, B., \& Bowman, C. (2005). Fostering Motivation, Learning, and Transfer in Multi-User Virtual Environments. Harvard Graduate School of Education. [Online] Available: http://muve.gse.harvard.edu/muvees2003/documents/Dede_Games_Symposium_AERA_2005.pdf(July 23, 2008).

Delwiche, A. (2003). MMORPG's in the College Classroom. The State of Play: Law, Games and Virtual Worlds. New York Law School. [Online] Available: http://www.nyls.edu/user_files/1/3/4/17/49/Delwiche.pdf (July 23, 2008).

English, F. W. (2000) Deciding what to teach and test. Developing, aligning and auditing the curriculum. Corwin Press, Inc.

Foreman, J., \& Borkman, T. (2007). Learning Sociology in a Massively Multistudent Online Learning Environment. In D. Gibson, C. Aldrich, \& M. Prensky (Eds.), Games and Simulations in Online Learning: Research and Development Frameworks. (pp. 49-58). Hershey, PA: Information Science Publishing.

Galarneau, L., \& Zibit, M. (2007). Online Games for 21st Century Skills. In D. Gibson, C. Aldrich, \& M. Prensky (Eds.), Games and Simulations in Online Learning: Research and Development Frameworks. (pp. 59-88). Hershey, PA: Information Science Publishing.

Gee, J. P. (2007). What video games have to teach us about learning and literacy. NewYork: Palgrave-McMillan.

Glasersfeld, E. V. (1989). Learning as a constructive activity. In P. Murphy, \& B. Moon (Eds.), Developments in learning and assessment. The Open University.

Jakobsson, M., \& Taylor, T.L. (2003). The Sopranos meets Everquest: Social networking in massively multiplayer 
online games. Proceedings of MelbourneDAC, the $5^{\text {th }}$ International Digital Arts and Culture Conference.

Jenlink, P. M., \& Jenlink, K. M. (2005) Portraits of teacher preparation: learning to teach in a changing America. Rowman \& Littlefield Education in partnership with the Association of Teacher Educators. Ketelhut, D. J., Dede, C., Clarke, J., Nelson, B., \& Bowman, C. (2006). Studying situated learning in a multi-user virtual environment. In E. Baker, J. Dickieson, W. Wulfeck \& H. O'Neil (Eds.), Assessment of problem solving using simulations. Mahwah, NJ: Lawrence Erlbaum Associates.

Kock, N. (ed)(2008). Encyclopedia of E-Collaboration. IGI Publishing. [Online] Available: http://common.books24x7.com.ezproxy.ied.edu.hk/book/id_13882/book.asp (December 9, 2008)

Lave, J., \& Wenger, E. (1991). Situated learning: Legitimate peripheral participation. New York: Cambridge University Press.

Law, F. (2005). School Leaders Gear Up For 334: High Level Professional Input and Collaboration to Sustain the Change. Speeches and Articles by Permanent Secretary for Education and Manpower Bureau of Hong Kong.

Lee, W.O. (1991). Social Change and Educational Problems in Japan, Singapore and Hong Kong. Macmillan.

Maddux, C., Johnson, D., \& Willis, J. (1997). Educational computing. Learning with tomorrow's technologies. (2nd ed.). Allyn \& Bacon.

Murphy, S. M. (2007). A Social Meaning Framework for Research on Participation in Social Online Games. Journal of Media Psychology, 12(3).

Prensky, M. (2006). Don't Bother Me Mom - I'm Learning!: how computer and video games are preparing your kids for twenty-first century success and how you can help!. Paragon House.

Reid, T.A. (1994). Perspective on computers in education: the promise, the pain, the prospect. Active Learning, CIT Support Service, Oxford, UK.

Sandholtz, J., Ringstaff, C. \& Dwyer, D. (1997). Teaching with technology. Creating student centred classrooms. Teacher College, Columbia University.

Shepard, L. A. (1997). Measuring achievement: What does it mean to test for robust understanding? William H. Angoff Memorial Lecture Series. Princeton, NJ: Educational Testing Service.

Slator, B., Clark, J., Daniels, L., Hill, C., McClean, P., Saini-Eidukat, B., \& White, A. (2002). Use of Virtual Worlds to Teach the Sciences. In L. Jain, R. Howlett, N. Ichalkaranje, \& G. Tonfoni (Eds.), Virtual Environments for Teaching \& Learning. World Scientific.

Steinkuehler, C.A. (2004). Learning in Massively Multiplayer Online Games. Paper presented at the International Conference of the Learning Sciences, Santa Monica, CA.

Stewart, T., Kemp, R., \& Batrum, P. (2001). Computerised Problem-Based Scenarios in Practice - A Decade of DIAGNOSIS. In T. Okanoto, R. Hartlet, Kinshuk \& J.P. Klus (Eds.) Proceedings: IEEE International Conference on Advanced Learning Technologies. 6-8 August 2001. Madison, Wisconsin, USA. IEEE Computer Society.

Sugumaran, V. (ed) (2008). Intelligent Information Technologies: Concepts, Methodologies, Tools, and Applications. IGI Publishing. [Online] Available: http://common.books24x7.com.ezproxy.ied.edu.hk/book/id_23490/book.asp ( December 9, 2008)

Wang, D. W. (2004). Enhancing interactivity and individualized learning in online learning environment: a literature approach. In R. Cheung, R. Lau, \& Q. Li (Eds.), New horizon in web-based learning: proceedings of the third International Conference on Web-Based Learning (ICWL 2004), Beijing, 8-11 August 2004. World Scientific.

Weeden, P., Winter, J., \& Bradfoot, P. (2002) Assessment. RoutledgeFalmer.

Williams, D., \& Skoricon, M. (2005). Internet Fantasy Violence: A Test of Aggression in an Online Game. Communication Monographs, 72(2), 217-233.

Wikipedia (2008). Virtual World for education. [Online] Available: http://en.wikipedia.org/wiki/Virtual_world\#Education (July 23, 2008).

Yee, N. (2006). The demographics, motivations and derived experiences of users of massively-multiuser online graphical environments. Presence: Teleoperators and virtual environments, 15(3), 309-329. 